\title{
Climate-Induced Variability of Sea Level in Stockholm: Influence of Air Temperature and Atmospheric Circulation
}

\author{
Deliang CHEN*1,2 and Anders OMSTEDT ${ }^{1}$ \\ ${ }^{1}$ Earth Sciences Centre, Göteborg University, Sweden \\ ${ }^{2}$ Laboratory for Climate Studies/National Climate Center, China Meteorological Administration, Beijing 100081
}

(Received 25 February 2005; revised 17 May 2005)

\begin{abstract}
This study is focused on climate-induced variation of sea level in Stockholm during 1873-1995. After the effect of the land uplift is removed, the residual is characterized and related to large-scale temperature and atmospheric circulation. The residual shows an overall upward trend, although this result depends on the uplift rate used. However, the seasonal distribution of the trend is uneven. There are even two months (June and August) that show a negative trend. The significant trend in August may be linked to fresh water input that is controlled by precipitation. The influence of the atmospheric conditions on the sea level is mainly manifested through zonal winds, vorticity and temperature. While the wind is important in the period January-May, the vorticity plays a main role during June and December. A successful linear multiple-regression model linking the climatic variables (zonal winds, vorticity and mean air temperature during the previous two months) and the sea level is established for each month. An independent verification of the model shows that it has considerable skill in simulating the variability.
\end{abstract}

Key words: sea level, Baltic sea, atmospheric circulation, temperature, Stockholm

\section{Introduction}

The global sea level over the last 100 years has risen at a rate close to $1-2 \mathrm{~mm}$ per year (Gornitz, 1993; Tsimplis and Woodworth, 1994; IPCC, 2001). Satellite data indicates (Nerem et al., 1997) that the rate of the global mean sea level change during recent years has been $+2.1 \pm 1.3 \mathrm{~mm}$ per year. It is obvious that even a few mm per year increase of sea level can have serious consequences on coastal environments (e.g., Titus and Narayanan, 1996). However, since sea level variations vary from region to region, a regional assessment is necessary if consequences of sea level change are to be described.

Sea level change can be studied by statistical and numerical modelling approaches which all need observations in some way. Tide gauges make the most straightforward measurements of sea level. These instruments measure the height of the sea relative to a nearby geodetic benchmark (Emery and Aubrey, 1991). Beyond instrument platform effects, subsidence or emergence of the land in the area or region at any specific location modifies the rate of relative sea level
(RSL) rise.

A long and continuous record of such a measurement plays a crucial role as the available long records show that sea level fluctuations that persist over decades are common (e.g., Douglas, 1992). This study deals with variability of RSL in Stockholm where the longest continued record in the world exists (Ekman, 1988).

Cui et al. (1995) identified three groups of causes for regional sea-level change: geological, regional dynamics and large-scale dynamics. The regional processes include the inverse barometric effect, the steric effect, the fresh water input, and the local atmospheric and oceanic circulation. In this study, a distinction between geological and climatic variability is made. This means that anything that is not geological, i.e., the regional dynamics and large-scale dynamics, is taken to be climatic.

For the Baltic as a whole, the water level driven in- and outflows through the Danish Straits have been identified as the primary forcing in the sea level change (Stigebrandt, 1980). This process in turn is forced by the zonal wind and the mean sea level of the North

\footnotetext{
*E-mail: deliang@gvc.gu.se
} 
Sea (Wroblewski, 1998a, b; Andersson, 2002). As the transport of water through the Danish Straits is affected by the wind over the Baltic entrance (Ekman, 1997) and the Danish Straits are shallow, there is a one-month time delay in the sea level change (Ekman, 1998). In a detailed study on sea level variation in the Baltic Sea, Samulsson and Stigebrandt (1996) pointed out that external forcing is the main cause for the variations on timescales longer than one month. More rapid external variations are filtered out due to the choking effect in the narrow entrance area. This finding justifies the use of monthly mean sea level to study the climate related sea level changes.

An attempt has been made to relate the monthly mean North Atlantic air-pressure to sea level anomalies in the Baltic Sea (Heyen et al., 1996). In a recent study, Plag and Tsimlis (1999) focused on decadal changes in the temporal variability of the annual and semiannual constituents in the sea level of the Baltic Sea in relation to a number of meteorological parameters. They conclude that the sea level, air pressure, air temperature and the wind field in the region are closely linked. All these studies demonstrate the importance of the atmospheric forcing to the sea level in the Baltic Sea. Since Stockholm is considered representative of the Baltic Sea (Wroblewski, 1998b), a further study on this time series with regard to atmospheric forcings is important for understanding the long-term variations of the water volume in the Baltic Sea. This study differs from the previous studies in that it aims at developing a skilful statistical model for the sea level in Stockholm for climate change studies. This model will incorporate the current understanding of the processes that have an impact on the sea level. In addition, it should be suitable for using useful information from GCMs to predict the changes in the sea level.

This study is focused on long-term climate-related variability of the sea level in Stockholm with special emphasis on identifying the role played by air temperature and atmospheric circulation. Stockholm is an ideal station to be studied, since the impact of internal variation is minimal. In fact, the station has been used as a reference station when the sea level in the Baltic was studied (Ekman, 1996). Moreover, it is interesting to note that while the sea level rise remains a practical issue for most of the world's coastal population, the sea level at Stockholm falls by about a few $\mathrm{mm}$ per year as land in the region continues to emerge in response to the disappearance of the ice there during the last deglaciation (Ekman, 1996). This implies that the climate-induced change in the RSL is superimposed on the trend caused by the land uplift.

The objectives of this study are: (1) to characterise the climate related variability of the relative sea level (RSL) rise; and (2) to determine the extent to which the climate related variability of the sea level is affected by the atmospheric temperature and circulation. The total sea level variability at Stockholm has been related to winter temperature in Stockholm and wind conditions in Lund (Ekman, 1998).

The datasets and methods used are described in section 2 . In section 3 , the climatic variability of the sea level in terms of monthly variability, seasonality, and long-term trend are described. Then a discussion on climate-induced sea level change is given. Also, a statistical model using atmospheric forcings as predictors is established and evaluated. Summary and conclusions are given in section 4 .

\section{Data and methods}

\subsection{Sea level data}

Ekman (1988) has documented the sea level data. The data in Stockholm (shown in Fig. 1) starts from 1774 and continues up to now. In the beginning, missing data are frequent. From 1825 onwards, the data is complete (Ekman and Stigebrandt, 1990). Data from 1873 to 1995 are used in this study. Monthly anomalies of sea level pressure (SLP) and RSL data are calculated based on the averages between 1961 and 1990 .

\subsection{Pre-processing of the RSL data}

Before the climate-induced change in the RSL can be studied, the geological component has to be removed. The geological process is usually assumed to be linear during the instrumental period and can be removed by a linear trend (e.g., Ekman, 1999). The RSL data consists of signals from eustatic, isosatic, and atmospheric and tectonic processes. In a review on sea level data worldwide, Fairbridge and Jelgersma (1990) pointed out that the Baltic Sea region is ideal for studying sea level change due to the fact that there

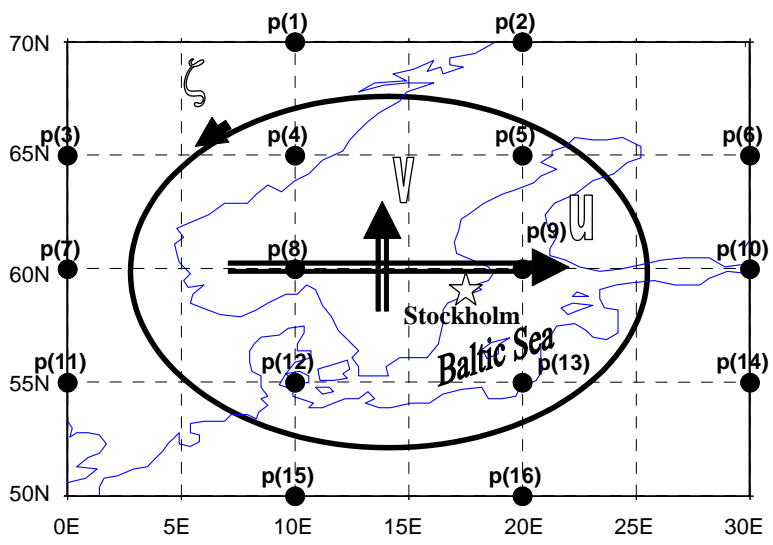

Fig. 1. Map showing the SLP gridpoints and the location of the Stockholm station. 
is extremely steady secular glacio-isostatic uplift, among other favourable reasons. This is confirmed by geodetic survey (Ekman, 1999). It is therefore assumed that the geological process is so slow that it can be considered linear on a timescale of a few centuries. When a linear trend appropriate to the glacio-isostatic and tectonic processes is subtracted from the original RSL, the residual signal may be assumed to be purely climatic. By climatic we mean the variability associated with atmospheric forcing and internal oceanic processes.

In the previous studies on the RSL at Stockholm, a linear trend was estimated based on a linear regression of the time series. This trend was then considered as representative of the land uplift effect. Then the detrended data were subject to further analysis. An obvious problem with this method is that a linear climatic trend would have also been removed. To overcome this problem, an independent estimate of the geological component is needed to keep the climate trend signal intact.

In this study, prior to the statistical analysis and modelling, the RSL data have been detrended by an independent estimate of the land uplift rate. The uplift rate at Stockholm estimated by Ekman (1996) based on the sea level records, lake records and repeated high precision levelling is used. Since the estimations via different methods for the period 1892-1991 agree well with each other for Stockholm, the estimated rate of $3.98 \mathrm{~mm} \mathrm{yr}^{-1}$ is considered reliable.

\subsection{Air pressure and circulation indexes}

To characterise the large-scale atmospheric circulation, Chen (2000) derived a monthly circulation climatology containing information about geostrophic wind and vorticity over Sweden. The atmospheric circulation is described by sea level pressure (SLP) over Scandinavia. The climatology gives a summary of circulation types and geostrophic wind conditions, which has been demonstrated as being useful for regional studies in Scandinavia (e.g., Blenckner and Chen, 2003). The application of the climatology for the Baltic Sea can be found in Omstedt and Chen (2001) and Omstedt et al. (2004a). The indices used in this study include zonal and meridional components of the geostrophic wind speed $(u$ and $v$ ) and the total geostrophic vorticity $(\xi)$ that are computed on a monthly basis using SLP at 16 grid points. The details of the definitions of the indices are given in Chen (2000). The SLP and the temperature data were compiled by the Climate Research Unit at the University of Norwich, which makes the data available on their website (http://www.cru.uea.ac.uk/cru/data/). Figure 1 shows the 16 points used to construct the in- dices. Instead of using grid point information for SLP and temperature, we choose to use the large scale indices and mean temperature in this study due to the following considerations: (1) we aim at developing a model for the sea level for climate change studies that rely on global climate models (GCMs); and (2) today's GCMs are skilful at scales larger than the grid point scale. The circulation indices used may be found at http://www.gvc.gu.se/ngeo/deliang/deliang.htm.

\subsection{Air temperature}

The gridded air temperature data compiled by Jones (1994) are used. They are on a $5^{\circ} \times 5^{\circ}$ gridbox basis. The data are expressed as anomalies with respect to 1961-90. A mean temperature covering the region between $55^{\circ} \mathrm{N}$ and $65^{\circ} \mathrm{N}$, and between $15^{\circ} \mathrm{E}$ and $25^{\circ} \mathrm{E}$, is used. This region covers most parts of the Baltic Sea and its size is comparable with today's global climate models (around $4 \times 4$ grids).

\subsection{Statistical modelling}

We have taken a two-step procedure to develop the final statistical model for RSL. First, all potential candidates of predictors (climatic variables) were screened to determine their relative importance to RSL. Then, a few of the most important predictors were chosen for establishing the final statistical model. The final model represents links between the sea level change and the large-scale atmospheric forcing with a multiple linear regression model. For the first step, the stepwise regression method is used to identify key predictors. With stepwise regression, the most important factor can be chosen as the first predictor. The second best predictor is chosen from among the predictors that are left, and so on. The number of predictors that are considered important is controlled by an $\mathrm{F}$ test. Predictors that pass the $95 \%$ significance level are considered.

The model is evaluated by verification with data from an independent dataset (data that were not used in developing the model). This is possible since the total data series is long enough to be split into two parts, with odd years $(1873,1875, \ldots, 1989)$ being used for development of the model and the even years $(1874,1876, \ldots, 1990)$ for the verification. Traditionally, a long time series is divided into two sub-periods with one sub-period being used for calibration and the other for verification. The strategy used in this study should in principle be superior to the traditional one in that climate variation over the whole period has a better chance of being included in the model development and verification. However, a test that splits the 
data into two equal parts gives similar results as the method used in this study.

\section{Results}

\subsection{Removal of the effect of land lift}

The anomaly of the detrended sea level data is constructed based on the base period of 1961-1990. All the anomalies used in this study were calculated on a monthly basis, i.e., the monthly means were removed. Figure 2 displays the annual anomaly which shows a long-term upward trend. A linear best fit of the anomaly gives an estimate of the trend as +0.22 $\mathrm{mm} \mathrm{yr}^{-1}$. After removal of the land-lift effect, the sea level does show an increasing trend, which is consistent with the general warming trend in the area. However, the trend is not significant at the $5 \%$ level. As can be seen in Fig. 2, the trend is mainly due to the increases since 1970. Furthermore, there is considerable low frequency variability as indicated by the 10-yr running mean, although the year-to-year variation is most obvious.

Of course, the magnitude of the climate-induced RSL long-term trend is highly sensitive to the estimate of the eustatic uplift rate, which is removed from the original RSL time trend shown in Fig. 2, which will be different if a different uplift rate is used. By dividing the Stockholm series into two periods (1774-1884 and 1885-1984), Ekman (1988) obtained two different trends that he called "apparent postglacial land uplift rates". The difference $\left(1.01 \pm 0.30 \mathrm{~mm} \mathrm{yr}^{-1}\right)$ was interpreted as being caused by climate change. This trend is greater than the one we obtained here, although the periods are slightly different. It is interesting to notice that the year dividing the two time periods of Ekman (1988) almost coincides with the change point in the ice climate identified by Omstedt and Chen (2001)

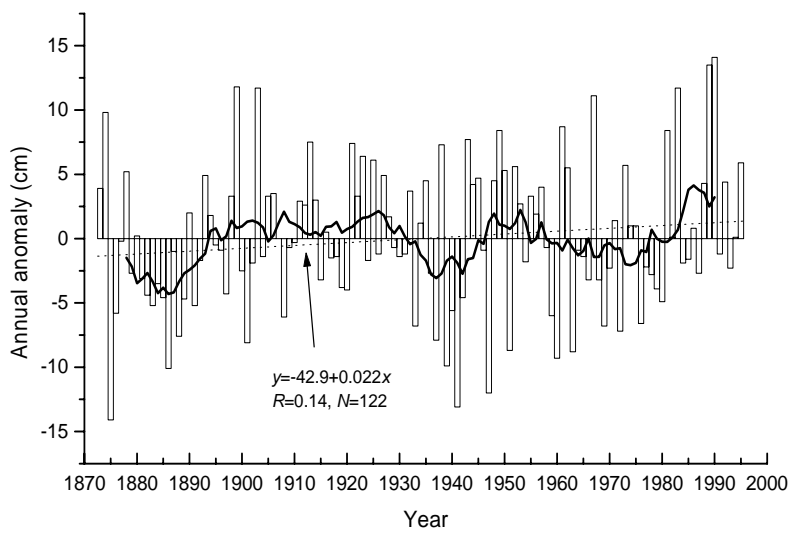

Fig. 2. Detrended (uplift effect removed) annual RSL anomaly in Stockholm. The baseline period is 1961-1990. The thick curve is the 10-yr running mean and the dotted line is the linear trend fitted by regression. corresponding to the end of the "Little Ice Age".

Another estimate of the uplift rate $(-4.92$ mm $\mathrm{yr}^{-1}$ ) was made by Ekman (1999) based on the sea level data. At this stage, it is difficult to judge which estimates are best. Fortunately, the trend is relatively small compared with the interannual variability. Thus the effect that different trends have on the following analysis is negligible.

\subsection{Monthly means, anomalies and trend}

To reveal the seasonal cycle of the climate-induced sea level changes, the monthly means and the associated standard deviation of the sea level describing its interannual variability are computed. Figure 3 displays the monthly and annual results. The detrended anomalies illustrate the well known (e.g., Samuelsson and Stigebrandt, 1996) seasonal cycle of sea level with higher sea level and larger variability during autumn and early winter compared to spring and summer.

In the last section, an upward trend was seen in the annual data. It is interesting to determine if there is a seasonal variation in the trend. Therefore, a linear regression is applied to anomalies in every month to estimate the monthly trends. The results are shown in Table 1. Based on the Pearson correlation coefficient, it is concluded that the estimated trends are not statistically significant at the $5 \%$ level. However, it is obvious that the positive annual trend is mainly caused by positive trends during the cold period between November and January. What was not known is the role played by the trend in April which is about three times larger than the annual one. Also interesting is the fact that there are two months (June and August) that show a negative trend. The negative

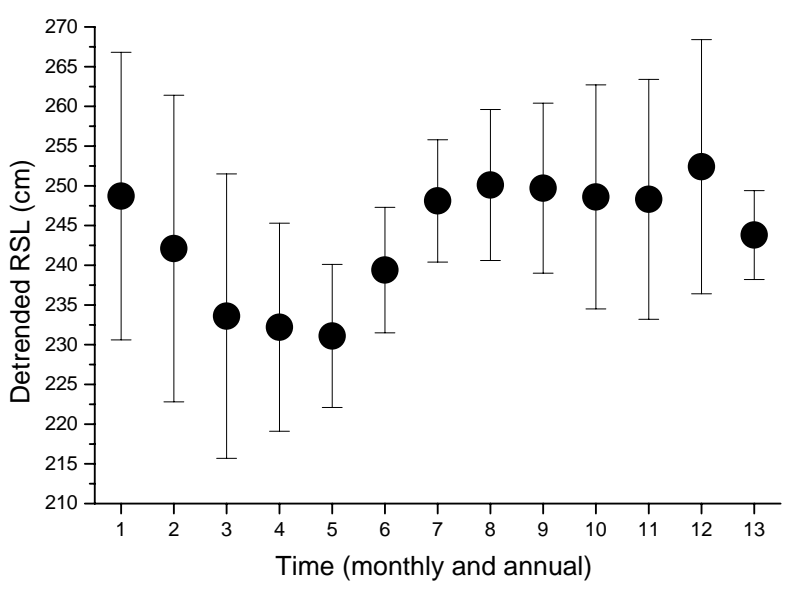

Fig. 3. Monthly and annual means of the detrended RSL in Stockholm during 1873-1995. 1-12 indicate January to December, while 13 gives the annual value. The error bars indicate the range of one standard deviation showing the interannual variability. 
Table 1. Monthly trends of the climate-induced variation in the RSL. The trend is established by a linear regression. The Pearson correlation coefficient $R$ shows how well the variations are represented by the linear trend.

\begin{tabular}{|c|c|c|c|c|c|c|c|c|c|c|c|c|c|}
\hline & Jan & Feb & Mar & Apr & May & Jun & Jul & Aug & Sep & Oct & Nov & Dec & Ann \\
\hline Trend $\left(\mathrm{mm} \mathrm{yr}^{-1}\right)$ & 0.8 & 0.0 & 0.0 & 0.7 & 0.0 & -0.2 & 0.1 & -0.5 & 0.1 & 0.3 & 0.8 & 0.7 & 0.22 \\
\hline$R$ & 0.17 & 0.0 & 0.0 & 0.19 & 0.0 & -0.09 & 0.06 & -0.18 & 0.02 & 0.07 & 0.19 & 0.15 & 0.14 \\
\hline
\end{tabular}

trend in August is fairly large and significant. It is interesting to note that a negative trend in precipitation in Sweden has also been found in August (Busuoic et al., 2001). Since the precipitation is linked to runoff that constitutes the fresh water supply to the Baltic, a possible explanation of the August decrease in the sea level may be the decreased precipitation. Another possible explanation is that the trends in water levels may reflect changes in the atmospheric circulation (e.g., Jacobeit et al., 2003; or Omstedt et al., 2004a). In the Baltic Sea region, the freshwater runoff from the river network is important (Fairbridge and Jelgersma, 1990; Omstedt et al., 2004b). In fact, sea level change in the Baltic is an output combining many individual effects. It would be ideal to work out a hydrological and geophysical budget for the various contributors to the sea level change.

In this study, the seasonal variations are examined with respect to changes in the air temperature and circulation only.

\subsection{Sea level change and air temperature}

Air temperature can influence the sea level directly through the effect of thermal expansion or indirectly if the temperature is correlated to, for example, circulation or the water balance. The different components of the Baltic Sea water balance are reviewed in Omstedt et al., (2004b), where the major components are identified as the in- and out-flows, river run-off and net precipitation. These components are closely related to atmospheric circulation and precipitation. The thermal expansion in the Baltic Sea due to seasonal cooling and warming has been estimated to be $2 \mathrm{~cm}$ (Stigebrandt, 2001). However, this rather small effect is caused by temperature change in the water, which implies that the timescale of the air-sea interaction is important in determining the thermal state of the water. Due to the relatively high heat capacity of water, the water temperature at a given time (month) may not only be influenced by the air temperature at that moment, but may also be cross-correlated with the air temperature of the previous months. A simple model to take this accumulating effect into account is a running average model in which air temperature is averaged over $\mathrm{k}$ months prior to a certain monthly value of RLS. To determine what the relevant timescale is, a series of mean temperatures with $k=1$ to 10 is computed and related to the RSL. By looking at the correlation coefficients, an optimal timescale of two months can be established. Figure 4 displays the results of the linear regression of RSL against running mean temperatures. Obviously a window of two months is optimal in terms of the correlation coefficient. At the same time, the sensitivity of the RSL to changes in the temperature is greatest when the two-month window is used. In a later analysis, the two-month running average for a given month rather than the monthly temperature itself is used.

An interesting question to ask is whether the upward trend in the RSL is due to the increase in the air temperature. However, due to the relatively large portion of the variability at short timescales (from interannual to interdecadal), a comparison between the RSL and the temperature trends should be interpreted with caution. Table 2 shows the long-term linear trend in the temperature. A general warming trend, except in February when a slight negative trend appears, can be identified. The most significant warming happens during March-June and October-December. The later period corresponds well with the significant increase in the sea level, while a similar signal in the former period cannot be found in the sea level. However, a simultaneous increase in the RSL and the temperature in April can be noted. These indicate that temperature is not the main factor that causes the upward trend of the

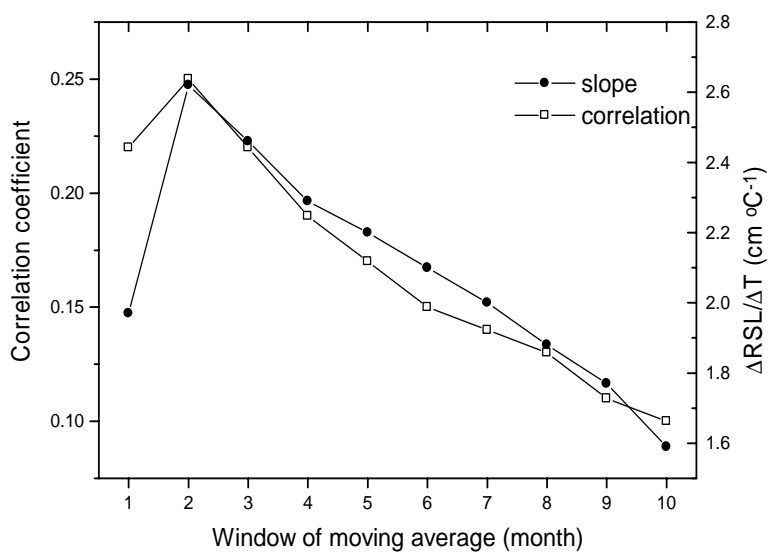

Fig. 4. Relationship between the running mean temperature with different time windows and the RSL. The Pearson correlation coefficient and the slope are shown on the left and right respectively. 
Table 2. Monthly trends of the large scale temperature. $R$ is the correlation coefficient.

\begin{tabular}{|c|c|c|c|c|c|c|c|c|c|c|c|c|c|}
\hline & Jan & Feb & Mar & Apr & May & Jun & Jul & Aug & Sep & Oct & Nov & Dec & Ann \\
\hline Trend $\left({ }^{\circ} \mathrm{C}(100 \mathrm{yr})^{-1}\right)$ & 0.09 & -0.10 & 1.0 & 1.0 & 2.0 & 1.0 & 0.0 & 1.0 & 0.1 & 1.0 & 1.0 & 1.0 & 1.0 \\
\hline$R$ & 0.02 & -0.02 & 0.22 & 0.3 & 0.41 & 0.24 & 0.09 & 0.17 & 0.03 & 0.27 & 0.21 & 0.20 & 0.30 \\
\hline
\end{tabular}

Table 3. The most important factor for each month, as identified by a stepwise regression. $N$ denotes the number of observations.

\begin{tabular}{ccccccccccccc}
\hline & Jan & Feb & Mar & Apr & May & Jun & Jul & Aug & Sep & Oct & Nov & Dec \\
\hline 1st predictor & $u_{-1}$ & $u_{-1}$ & $u$ & $u_{-1}$ & $u$ & $\xi$ & $\xi$ & $\xi$ & $\xi$ & $\xi$ & $u-1$ & $\xi$ \\
$R(N=122)$ & 0.55 & 0.70 & 0.64 & 0.56 & 0.54 & 0.55 & 0.43 & 0.59 & 0.53 & 0.63 & 0.56 & 0.60 \\
\hline
\end{tabular}

RSL.

\subsection{Linkage between the RSL and circulation}

Another factor that may contribute to the changes in the RSL is the atmospheric circulation. The interannual variability of the Stockholm sea level has been related to the air temperature in Stockholm and wind conditions in Lund (Ekman, 1998). Since the longterm variation is strongly influenced by the variations in the North Sea, the wind over the transition zone between the North Sea and the Baltic Sea has an important effect on the sea level in Stockholm (e.g., Gustafsson and Andersson, 2001). Ekman (1998) identified several combinations of the temperature and wind conditions that have a distinctive effect on the sea level. However, as the combination stresses on extreme conditions, a generalization is difficult.

Here, a stepwise regression is used to identify potentially important circulation indices for the RSL. All the circulation indices $(u, v, \zeta)$ during a given month and the previous month are used as candidates. This choice is motivated by the previous finding that there is a one month time delay between the zonal wind and the sea level change in Stockholm (Ekman, 1998). The most significant factor in terms of correlation coefficient for each month is listed in Table 3. It is interesting to note that only zonal wind and vorticity appear. Also, often it is the zonal winds one month before that play a significant role. The effects of zonal winds appear to be in the cold season, while the effects of vorticity dominate during the warm season. During the cold season, the temperature is closely connected to the zonal wind (e.g., Chen and Hellström, 1999). The relatively high correlation between the zonal wind and the temperature during the cold months can explain the highest sensitivity of RSL to temperature. At the same time, the vorticity in the given month appears as the most important factor in the warm season. This is an interesting result since the RSL change cannot be explained by temperature. Vorticity has been identi- fied as the most important factor in determining the precipitation in Sweden (Hellström et al., 2001), which implies the role of fresh water input to the Baltic Sea.

To determine whether other indices and temperature are significant contributors to RSL change, a stepwise linear regression for each month is performed. The results of the monthly regression show that a group of significant predictors (at the $5 \%$ significance level) including $u, v, \xi$ in the current month, and $u_{-1}$ and $\xi_{-1}$ in the previous month, plus the temperature play a significant role. A statistical model liking RSL and these significant factors will be established in the next section.

\subsection{Statistical modelling of $R S L$ in relation to temperature and circulation}

It has been established that the atmospheric circulation plays a more important role than the temperature in determining the RSL. To quantitatively determine their relative importance, a multiple linear regression can be used. Here, we assume that the model takes the following form:

$$
L_{\mathrm{RS}}=A_{0}+\sum_{i=1}^{6} A_{i} X_{i}
$$

where $A_{i}, i=0, \ldots, 6$ are the coefficients determined by regression and $\mathrm{X}_{i}, i=1, \ldots, 6$, are the predictors $u_{-1}, \xi_{-1}, u, v, \xi$ and $T$ respectively. Table 4 summarizes the regression results. Looking at the correlation coefficients, the model fits the observations satisfactorily, though in the summertime, it shows less skill. It can be seen that the vorticity and zonal wind in the present and previous months affect the RSL in a consistent way, reflected by the same sign of the associated coefficients. The stronger the west winds, the higher the sea level. The same is true for the vorticity, which means that strong low (high)-pressure systems are associated with higher (lower) sea level. This indicates that wind effects are more important forcing mecha- 


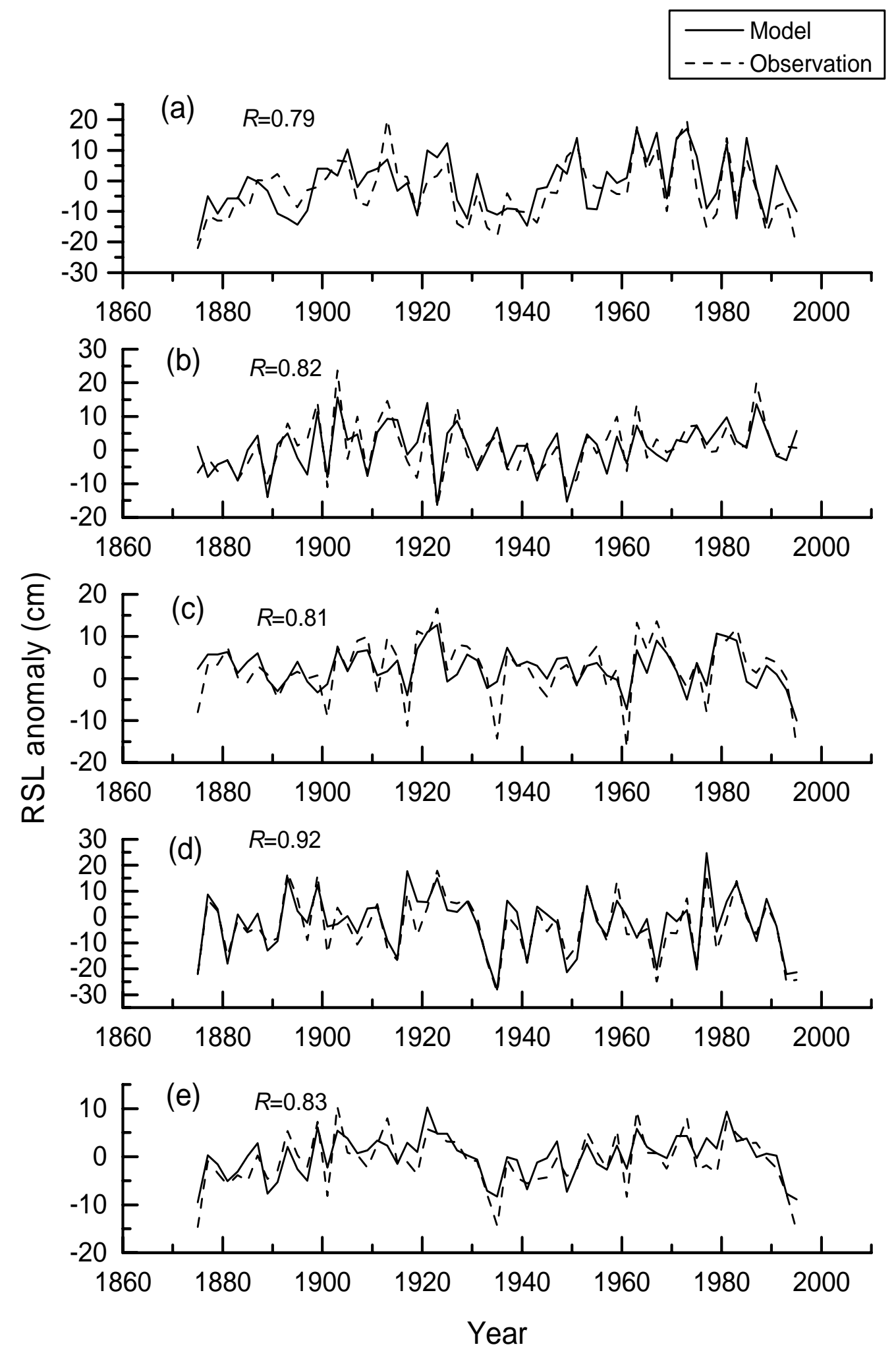

Fig. 5. Performance of the statistical model (independent verification) in comparison with seasonal and annual observations: (a) MAM; (b) JJA; (c) SON; (d) DJF; (e) Annual. The model was calibrated using data from odd years, while the verification results here use values from even years $(1874,1876, \ldots, 1990)$. 
Table 4. Monthly regression coefficients and the multiple correlation coefficients of the multiple linear regression model for calibration $\left(R_{1}\right)$ and verification $\left(R_{2}\right)$. The squared correlation coefficients can be interpreted as the percent of the total variance in RSL explained by the predictors.

\begin{tabular}{|c|c|c|c|c|c|c|c|c|c|}
\hline & $A_{0}$ & $A_{1}\left(u_{-1}\right)$ & $A_{2}(\xi-1)$ & $A_{3}(u)$ & $A_{4}(v)$ & $A_{5}(\xi)$ & $A_{6}(T)$ & $R_{1}$ & $R_{2}$ \\
\hline Jan & -0.08 & 1.4 & 0.52 & 0.62 & -0.22 & 0.82 & 0.85 & 0.88 & 0.87 \\
\hline Feb & -1.59 & 0.98 & 0.21 & 1.07 & -0.09 & 0.58 & 2.26 & 0.88 & 0.85 \\
\hline Mar & 0.32 & 0.88 & 0.38 & 1.62 & -0.50 & 0.91 & 1.60 & 0.92 & 0.89 \\
\hline Apr & 0.30 & 1.07 & 0.31 & 1.36 & -1.01 & 0.44 & 0.80 & 0.86 & 0.83 \\
\hline May & -0.29 & 0.99 & 0.30 & 1.59 & 0.13 & 0.45 & 0.38 & 0.83 & 0.68 \\
\hline Jun & 0.15 & 0.17 & 0.15 & 1.19 & -0.48 & 0.57 & 0.30 & 0.74 & 0.71 \\
\hline Jul & -1.13 & 0.71 & 0.12 & 1.42 & -0.82 & 0.40 & 0.06 & 0.65 & 0.73 \\
\hline Aug & 0.05 & 0.96 & 0.23 & 0.75 & -0.25 & 0.62 & 0.20 & 0.74 & 0.78 \\
\hline Sep & -0.99 & 1.20 & 0.38 & 0.91 & -0.43 & 0.73 & -0.11 & 0.80 & 0.77 \\
\hline Oct & 0.55 & 1.13 & 0.44 & 1.27 & -0.23 & 0.75 & 1.03 & 0.87 & 0.90 \\
\hline Nov & -1.06 & 1.26 & 0.59 & 0.82 & -0.34 & 0.79 & 0.58 & 0.87 & 0.88 \\
\hline Dec & -0.53 & 1.23 & 0.43 & 1.13 & -0.53 & 0.81 & 0.52 & 0.86 & 0.81 \\
\hline Mean & -0.36 & 1.00 & 0.34 & 1.15 & -0.40 & 0.66 & 0.71 & 0.82 & 0.81 \\
\hline
\end{tabular}

nisms during the wintertime while changes in atmospheric pressure dominate during the warmer season. Statistically, the zonal winds in the present month and previous month are nearly equally important, while the vorticity in the present month is much more important than that of the previous month. This indicates that either the large-scale circulation has an autocorrelation of less than 2 months or the large-scale circulation of the previous month triggers processes which affect the sea level in the present month. The meridional wind seems to be anti-correlated with the sea level, except in May. Generally, the temperature has a positive effect on RSL. The mean sensitivity of RSL to temperature changes is much smaller than that established previously when the effect of the circulation was taken into account. This indicates that the temperature is correlated with the circulation and much of the temperature information is reflected in the circulation.

The skill of the model is demonstrated by the high correlation coefficients $\left(R_{1}\right)$ of the regression listed in Table 4 . To confirm this, the model is verified against the other half of the observations. The last column in Table 4 shows the correlation coefficients for the verification $\left(R_{2}\right)$. The $R_{2}$ values are similar to $R_{1}$, which indicates that the model is robust and stable. Figure 5 compares the modelled and observed RSL on the seasonal and annual bases. For all the seasons, the modelled series follow the observed ones fairly well. This independent test approves the validity of the model.

\section{Summary and conclusions}

This study deals with the climate related variability of the sea level at Stockholm and its relation to large-scale temperature and atmospheric circulation. Based on the analysis of the climatic signal (after the land uplift effect has been removed) and the statistical modelling of the relationship between the climatic signal and the two climate variables, the following conclusions may be drawn:

(1) The climate-induced change in the sea level during 1873-1995 shows an upward trend of 0.22 $\mathrm{mm} \mathrm{yr}^{-1}$. However, the seasonal distribution of the trend is uneven. While positive trends appear during November-January and in April, there are two months (June and August) that show a negative trend. The significant trend in August may be linked to fresh water input that is controlled by precipitation. A detailed study on the hydrological and geophysical budget of the sea level change is needed to resolve the issue.

(2) The influence of the atmospheric circulation on the sea level is mainly manifested through zonal winds and vorticity. While the wind is important in the period January-May, the vorticity (indicating a high or low pressure system over the Baltic sea) plays a main role during June and December. The one-month delay of the sea level after the zonal wind, discovered by previous study, is confirmed. The effect of meridional wind is negligible.

(3) A linear multiple-regression model linking the climatic variables (zonal wind, vorticity and the mean air temperature during the past two months) and the sea level has been established for each month. An independent verification of the model shows that it has considerable skill in predicting the variability. This model may be used to construct future scenarios based on GCM outputs.

Acknowledgments. This work was a part of the 
Swedish regional climate modeling program (SWECLIM) and Global Energy and Water Cycle Experiment/The Baltic Sea Experiment (GEWEX/BALTEX) programmes, and has been funded by MISTRA and SMHI within the SWECLIM program and by Göteborg University and the Swedish Research Council (Contract G 600-335/2001). It was also partly supported by two Swedish Sciences Council (NFR/VR) grants to Deliang Chen. Youmin Chen is acknowledged for providing the stepwise regression program.

\section{REFERENCES}

Andersson, H. C. 2002: Influence of long-term regional and large-scale atmospheric circulation on the Baltic sea level. Tellus, 54A, 76-88.

Blenckner, T., and D. Chen, 2003: Comparison of the impact of regional and North-Atlantic atmospheric circulation on an aquatic ecosystem. Climate Research, 23, 131-136.

Busuioc, A., D. Chen, and C. Hellström, 2001: Temporal and spatial variability of precipitation in Sweden and its link with the large scale atmospheric circulation, Tellus, 53A, 348-367.

Chen, D. 2000: A monthly circulation climatology for Sweden and its application to a winter temperature case study. International Journal of Climatology, 20, 1067-1076.

Chen, D., and C. Hellström, 1999: The influence of the North Atlantic oscillation on the regional temperature variability in Sweden: Spatial and temporal variations, Tellus, 51A, 505-516.

Cui, M., H. Storch, and E. Zorita, 1995: Coastal sea level and the large-scale climate state: A downscaling exercise for the Japanese Islands. Tellus, 47A, 132-144.

Douglas, B. C., 1992: Global sea level acceleration. J. Geophys. Res., 97(C8), 12 699-12 706.

Ekman, M., 1988: The world's longest continued series of sea level observations. Pure and Applied Geophysics, 127, 73-77.

Ekman, M., 1996: A consistent map of the postglacial uplift of Fennoscadia. Terra Nova, 8, 158-165.

Ekman, M., 1997: Anormalous winter climate coupled to extreme annual means in the Baltic sea level during the last 200 years. Small Publications in Historical Geophysics, 3, 1-14.

Ekman, M., 1998: Long-term changes of interannual sea level variability in the Baltic sea and related changes of winter climate. Small Publications in Historical Geophysics, 5, 1-14.

Ekman, M., 1999: Climate changes detected through the world's longest sea level series. Global and Planetary Change, 21, 215-224.

Ekman, M., and A. Stigebrandt, 1990: Secular change of the seasonal variation in sea level and of the pole tide in the Baltic Sea. J. Geophys. Res. , 95(C4), 53795383.

Emery, K. O., and D. G. Aubrey, 1991: Sea Levels, Land Levels, and Tide Gauges. Springer-Verlag, New York, $237 \mathrm{pp}$.

Fairbridge, R. W., and S. Jelgersma, 1990: Sea level. Greenhouse Effect, Sea Level and Drought, R. Paepe et al., Eds., Kluwer Publishers, Dordrecht, 117-143.
Gornitz, V., 1993: Mean sea level changes in the recent past. Climate and Sea Level Change: Observations, Projections and Implications, R. A. Warrick et al., Eds, Cambridge University Press, Cambridge, 25-44.

Gustafsson, B. G., and H. C. Andersson, 2001: Modeling the exchange of the Baltic Sea from the meridional atmospheric pressure difference across the North Sea. J. Geophys. Res., 106(C9), 19 731-19 744.

Hellström, C., D. Chen, Ch. Achberger, and J. Räisänen, 2001: A comparison of climate change scenarios for Sweden based on statistical and dynamical downscaling of monthly precipitation. Climate Research, 19, $45-55$.

Heyen, H., E. Zorita, and H. Storch, 1996: Statistical downscaling of monthly mean North Atlantic airpressure to sea level anomalies in the Baltic Sea. Tellus, 48A, 312-323.

IPCC, 2001: Climate Change 2001-The Scientific Basis. Contribution of Working Group I to the Third Assessment Report of the Intergovernmental Panel on Climate Change, J. T. Houghton et al., Eds., Cambridge University Press, Cambridge, United Kingdom, and New York, USA, 881 pp.

Jacobeit, J., H. Wanner, J. Luterbacher, C. Beck, A. Philipp, and K. Sturm, 2003: Atmospheric circulation variability in the North-Atlantic-European area since the mid-seventeenth century. Climate Dyn., 20, 341-352.

Jones, P. D., 1994: Hemispheric surface air temperature variations: A reanalysis and an update to 1993. J. Climate, 7, 1794-1802.

Nerem, R. S., B. J. Haines, J. Hendricks, J. F. Minister, G. T. Mitchum, and W. B. White, 1997: Improved determination of global mean sea level variations using TOPEX/POSEIDON altimeter data. Geophys. Res. Lett., 24, 1331-1334.

Omstedt, A., C. Pettersen , J. Rodhe, and P. Winsor, 2004a: Baltic Sea climate: 200 years of data on air temperature, sea-level variation, ice extent, and atmospheric circulation. Climate Research, 25, 205-216.

Omstedt, A., J. Elken, A. Lehmann, and J. Piechura, 2004b: Knowledge of the Baltic Sea Physics gained during the BALTEX and related programmes. Progress in Oceanography, 63, 1-28.

Omstedt, A., and D. Chen, 2001: Influence of atmospheric circulation on the maximum ice extent in the Baltic Sea, J. Geophys. Res., 106(C3), 4493-4500.

Plag, H.-P., and M. N. Tsimplis, 1999: Temporal variability of the seasonal sea-level cycle in the North Sea and Baltic Sea in relation to climate variability. Global and Planeatry Change, 20, 173-203.

Samuelsson, M., and A. Stigebrandt, 1996: Main characteristics of the long-term sea level variability in the Baltic Sea. Tellus, 48A, 672-683.

Stigebrandt, A., 1980: Barotropic and baroclinic response of a semi-enclosed basin to barotropic forcing from the sea. Fjord Oceanography, H. J. Freeland, D. M. Farmer, and C. D. Levings, Eds, Plenum, New Yourk, 151-164.

Stigebrandt, A., 2001: Physical Oceanography of the Baltic Sea. Chapter 2, A Systems Analysis of the Baltic Sea, F. Wulff, L. Rahm, and P. Larsson, Eds., Springer-Verlag, Berlin, Heidelberg, Germany, 19-74.

Titus, J. G., and V. Narayanan, 1996: The Risk of Sea Level Rise. Climatic Change, 33, 151-212. 
Tsimplis, M. N., and P. L. Woodworth, 1994: The global distribution of the seasonal sea level cycle calculated from coastal tide gauge data. J. Geophys. Res., 99(C8), 16 031-16 039.

Wroblewski, A., 1998a: The effect of the North sea on os- cillations of the mean monthly sea levels in the Baltic sea. Cont. Shelf Res., 18, 501-514.

Wroblewski, A., 1998b: Inter-annual oscillations of Baltic water volumes and sea levels. Oceanologia, 40(3), 121 . 